\title{
The Digitization of Active Surveillance: an Insight- Based Evaluation of Interactive Visualization of Active Case Search for Polio Surveillance to Support Decision Making in Africa
}

\section{Godwin Akpan ( $\square$ akpang@who.int )}

World Health Organization , Regional Office for Africa ,Brazzaville, Congo Isah Bello

World Health Organization, Regional Office for Africa ,Brazzaville, Congo Hani Farouk Mohamed

World Health Organization, Regional Office for Africa ,Brazzaville, Congo Kebba Touray

World Health Organization, Regional Office for Africa ,Brazzaville, Congo John Kipterer

World Health Organization , Regional Office for Africa ,Brazzaville, Congo

Reuben Ngofa

World Health Organization , Regional Office for Africa ,Brazzaville, Congo

Daniel Oyaole

World Health Organization - Nigeria

Ajiri Atagbaza

World Health Organization , Regional Office for Africa ,Brazzaville, Congo

Johnson Ticha

World Health Organization , Regional Office for Africa ,Brazzaville, Congo

Casimir Manengu

World Health Organization, Regional Office for Africa ,Brazzaville, Congo

Chanda Chikwanda

World Health Organization, Regional Office for Africa ,Brazzaville, Congo

Marie Babona Nshuti

World Health Organization , Regional Office for Africa ,Brazzaville, Congo

Semeeh Omoleke

World Health Organization - Nigeria

David Oviaesu

World Health Organization - Nigeria

Mamadou Diallo

World Health Organization, Regional Office for Africa ,Brazzaville, Congo 


\section{Vincent Seaman}

Bill \& Melinda Gates Foundation

\section{Pascal Mkanda}

World Health Organization , Regional Office for Africa ,Brazzaville, Congo

\section{Research Article}

Keywords: Interactive visualizations, user experience, polio, real-time, Active Surveillance, decision making Posted Date: December 18th, 2020

DOl: https://doi.org/10.21203/rs.3.rs-112805/v1

License: (c) (1) This work is licensed under a Creative Commons Attribution 4.0 International License. Read Full License 


\section{Abstract}

Background: Tracking every child for polio eradication in the African region has been an ambitious objective in respose to the recommendations of the Global Polio Eradication Initiative (GPEI) to enhance information gathering in areas with sub-optimal and challenging performance. Achieving this objective require real-time information on active surveillance. Acute Flaccid Paralysis (AFP) case searches were captured on mobile phones to monitor polio eradication programme through a digitalised platform developed by the Polio Geographic Information System Centre at WHO Regional Office for Africa. The system generated a huge dataset and influenced the development of several information products that was critical for managing the polio programme within the African region which was acknowledged by Africa Regional Certification Commission (ARCC) as a key support to acheivng eradication of wild polio virus which was celebrated in August 2020.

Objective: To document and assess the impact of interactive visualisation infographic platforms to guide decision-making in achieving polio eradication in the African continent

Method: The study reviewed retrospective prototype data from a web-based interactive visualization platform sourced from real-time active case searches (ACS) conducted in the African region from June 2017-2020 using android mobile phones. The study participants used the platform via smart screens and touch wall projections for decision making and gap analyses. The study evaluated the tool using the informal user experience evaluation method combined with an automated relay monitor on the active surveillance web-based applications, which cached every visit to the geographic entity. The method employed required platform users to interrelate with ACS and AFP surveillance data via visual displays for their programmatic interventions and accountability. The study also captured their feedbacks through a structured interview and automatically-cached pages.

Results: Communicating field level indicators in real-time and interactively to decision-makers is a powerful and veritable tool to solve geographical representation of surveillance gaps at the lowest level of reporting, and reach a wider diversity of audience. These interactive visualisations also solve the problem of complexity in interpretation, which can lead to an impaired understanding of surveillance blind spots, information misinterpretation, which occurs when users of the surveillance data ignore or do not know why, where, and how the data has been produced, or where and how it can be used.

Conclusion: The digitalization of disease surveillance, particularly, ACS for Poliomyelitis permits decisionmakers to conduct a strategic evaluation of surveillance situations and gaps via interactive visualisations. In this context, these interactive visualisations provide polio programme in Africa wih a platform to visualise interactive imageries of geographical evidence of active surveillance at focal sites using interactive charts, maps and dashboards for all polio surveillance processes. Other considerations, such as cost, ease of use, learnability, and efficiency of those tools were comparatively better than the traditional system. 


\section{Background}

Policy-makers driving polio eradication require timely, precise, integrated, multifaceted information from country polio networks to adequately develop strategies that could halt poliovirus transmission(1).

Previously, this elaborate network primarily included data from the four core strategies of the Global Polio Eradication Initiative (GPEI); surveillance, immunization, outbreaks and containment(2). However, comprehensive decision making is not limited to but involves an understanding of challenges in delivering immunization due to conflict, geographically or culturally hard-to-reach populations and systemic health barriers that hinder eradication efforts(3). Tracking every child for polio eradication in the African region has been an ambitious objective in respose to the recommendations of the Global Polio Eradication Initiative (GPEI) to enhance information gathering in areas with sub-optimal and challenging performance. Achieving this objective require real-time information on active surveillance

Previously, a paper-based system was used by various thematic areas within the polio eradication programme. For example, supportive supervision and active case searches (ACS) conducted by surveillance officers were documented on paper (hard copy), despite the significance of these activities as a prerequisite for regional polio certification. The system was marred with delays in information delivery, time-consuming, and was unverifiable, frustrating efforts at both country and regional levels for public health action. As a result, the Polio Eradication Programme at the World Health Organisation Regional Office (PEP AFRO) developed a web-based Geospatial Information System (GIS) that visually integrated key programme predictive values from critical polio eradication indicators to inform inter-regional and country polio eradication managers on progress towards polio eradication, in real-time $(4,5)$.

The end game for polio has birthed innovative approaches to managing polio surveillance interventions and the emergency nature of the programme(6). One of the innovative approaches is the digital health initiative designed to overcome the surveillance hurdles faced at all levels. Thus, interventions like AutoVisual AFP Detection and Reporting (AVADAR), electronic Surveillance (e-Surve), Integrated Supportive Supervision (ISS), Lot Quality Assurance Sampling (LQAs) and Independent Monitoring (IM) and Environnmental Surveillance (ES)data could be streamed into aggregation servers from 44 countries in the African Region by the minute(7). Therefore, it becomes imperative that the traditional offline database analytical systems that were manually merged together to form weekly reports can no longer suffice for real-time analyses and decision making.

Based on the above-mentioned justifications, we examined the contribution(s) of the novel Smart Interactive Visualizations (SIVs) to the polio eradication programme. We explored the benefits of conducting ACS for AFP using android or smartphones for visualisation to demonstrate accountability, identify potential gaps, and make real-time decisions and communication for the polio eradication programme. Considering the above, this study sets out to achieve the following six goals of digitising active surveillance in the African region by demonstrating the following elements/deliverables:

i. Real-time feedback and transparent decision-making process from evidence-based surveillance 
ii. Demonstrated accountability enabled system

iii. Overlaying capabilities to compare surveillance indicators - output versus process indicators

iv. Interactivity - ease of relating to the data dynamically in maps and dashboards

$v$. Increase of reach and use of the data by partners

These deliverables also form the bases of the results the study is set out to evaluate.

\section{Methods}

\section{Study design}

A web-based polio eradication monitoring platform was devised from an existing widely-used paperbased questionnaire and uploaded to an Open Data Kit (ODK). The application contains questions related to surveillance that are routinely administered by surveillance officers and health workers to access active surveillance in predefined, prioritised health facilities.

The study reviews a retrospective prototype data from an online interactive visualization platform representing real-time active case searches (ACS) conducted in 44 of the 47 countries in the African region from 2017 to 2020(8). The study participants are country program managers and frontline health workers in countries conducting electronic-based active surveillance, using mobile phones and interacting with visualised data. The visualised data is displayed via smart screens and touch wall projections for decision making and gap analyses. The tool was evaluated using an informal user experience evaluation method. The method involves the users of the platform interacting with active case search and AFP surveillance data via visual displays for their programmatic interventions focusing on accountability. The study collected their feedbacks through interviews.

The study developed a decision support tool (Analytica) that aggregated the data from countries and automatically displayed it on maps, charts and dashboards and with complex datasets parsed through Action Programming Interfaces(API) $(9,10)$ to Business Intellegence (BI) platforms (i.e. Tableau, Power BI) and ArcGIS online (11-14). To interactively harness these data, the African regional office rolled out interactive smart screens to be used to display the data to be panned, sliced and diced by simple touching on the screen(15).

In developing these systems for digitisation and visualisation, the polio program considered the bridges between Science, Society and Policy to harness the implemented technologies. The illustration for the design methodology is shown in figure 1, from goal settings to design to implementation and outcomes, then measuring the impact on the surveillance programme (16).

\section{Data Management}

\section{Choice of Open Data Kit}


Open Data Kit ( ODK) has been the first software of choice for collecting large data on mobile phones, especially in low-resource settings, such as Africa (17)(18)(19). The active case surveillance forms were translated from paper format into ODK format and uploaded on mobile phones for all countries in the region through selected focal points. The selected focal points have good knowledge of the active surveillance processes and are able to manage minor ICT procedures. Data aggregation servers (DAS) were utilized using documentation guidelines built from the Nigerian experience of large data expeditions to harness all these data from mobile phones in the hands of health workers in the region in real-time(8). ONA-ODK server software was installed on the servers to receive the data for all countries into a regional server called Analytica with considerations of security and data integrity at the heart of the deployment.

\section{Managing the surveillance data-processes}

Data Management is vital in guiding public health interventions (20). It is important to ensure that all the data from the surveillance interventions are validated, secure and accessible across all devices and operating systems (OS) from mobile devices (e.g. phones to desktops and laptops. Thus, all the countries can access their data through their secure administrative and read-only profiles in all formats, such as $\mathrm{XLS}, \mathrm{CSV}, \mathrm{OSM}, \mathrm{KML}$ among othersImportantly, simple analyses of the data is done and previewed in charts and dashboard, using clojure (21) and pre-implemented on the web platform, emphasising the geography of the visits automatically aggregated into interactive maps. The program primed the preliminary visualisation tool as part of the server installation to ensure that maps and charts can dynamically display the data as it arrives at the data aggregation servers.

The preliminary visualization tools embedded in most data aggregation servers were limited in displays and decision-making capabilities (10). Hence, the system utilized Application Programming Interfaces (APIs) on the servers to tunnel and export data to the third party visualization servers capable of triangulating complex data and presenting in a-very-easy-to-understand-formats and improved decisionmaking. Business Intellegence platforms (i.e. Tableau and Power BI) connectors were developed and automatically installed on the servers to manage big data from active surveillance reporting. The polio program further harnessed the innovation of bringing real-time data from active surveillance using light operating system hardware in integration with interactive Smart Television. WHO trained Data and ICT Managers, installed two smart Televisions with these capabilities to render active surveillance visits in real-time in all the countries in the WHO African Region. WHO installed Smart Televisions at the Ministries of Health and at the WHO Country Offices (WCO) in designated user areas to allow for discussions and interactions with these data (10)

Gap analyses were automatically configured by maps and overlaid data, and it is visualized in real-time on the smart screens, and it is also available on personal computers and mobile phones. Also, alerts are disseminated as e-mail triggers and Short Message Service (SMS) of shortfalls or changes in important variables being tracked at the field level are received. An illustrative example is the case of missed AFP case(i.e., not notified by health workers at the visited health facilities) once the data records are submitted to the server, the server triggers generate an e-mail and send it to the involved focal person(s) and other 
accountable officers responsible for processing or managing the AFP surveillance system to take the proper action(22).

\section{Training and monitoring}

Furthermore, the study trained country teams on the use of these technologies. Surveillance officers, specifically, District Servielance Notiviation Officers (DSNOs), are trained on the use of mobile phones at the health facility level to conduct active surveillance. Senior surveillance officers and data managers are sensitised at national and sub-national levels on the aggregation servers and activating accountability frameworks to improve staff accountability.

At the WHO African Regional Office, the use of the data for action is also being evaluated via feedback shared with member States using the aggregated data to tease out the surveillance gaps and assess surveillance staff accountability at all levels. This web-based feedback is monitored for traffic, utilisation and retention of users by countries.

\section{Data analysis}

The study downloaded the summarised and digitised data generated from 44 African countries for key data variables showing the changes, improvements and gaps in surveillance. The study used a paired Sample t-Test to compare the data for digitized active surveillance and paper-based active surveillance (before digitized surveillance). The study also aggregated the digitised surveillance data to produce regional, national and sub-national (i.e. provential and district) level maps to illustrate silent areas and poor performing levels. To gain a better perspective on surveillance processes to output performance, the polio program superimposed the Non-Polio AFP rate (NPAFPR). Figue 2 illustrates the adopted workflow process, utilized servers and tools for achieving electronic active surveillance.

\section{Results}

Table 1 shows an average reporting time of 8.7hours for electronic reporting compared to 87.6 hours for the paper-based reporting. Similarly, the turn-around time from visit to electronic databases (absorption time) was found to be 8.34 days for the digitized surveillance reporting against 30 days for the paperbased reporting system.

\section{Table 2 Sample T-paired analyses of paper based vs digitized surveillance parameters}




\begin{tabular}{|lllll|}
\hline & $\begin{array}{l}\text { Paper-based Active } \\
\text { Surveillance(Avg time } \\
\text { hrs) }\end{array}$ & $\begin{array}{l}\text { electronic } \\
\text { Surveillance(Avg } \\
\text { time hrs) }\end{array}$ & $\begin{array}{l}\text { Paper Database } \\
\text { Absorption time }\end{array}$ & $\begin{array}{l}\text { electronic } \\
\text { database } \\
\text { absorption time }\end{array}$ \\
\hline Mean & 86.27272727 & 8.659090909 & 30 & 8.344289915 \\
\hline Variance & 2917.505285 & 34.09038055 & 0 & 296.1233458 \\
\hline Observations & 44 & 44 & 44 & 44 \\
\hline $\begin{array}{l}\text { Pearson } \\
\text { Correlation }\end{array}$ & 0.373579273 & & 0 & \\
\hline $\begin{array}{l}\text { Hypothesized } \\
\text { Mean } \\
\text { Difference }\end{array}$ & 0 & & 0 & \\
\hline $\begin{array}{l}\text { Df } \\
\text { t Stat }\end{array}$ & 43 & & 43 & \\
\hline $\begin{array}{l}\text { P(T<=t) one- } \\
\text { tail }\end{array}$ & 0.000000000000624 & & 8.347615621 & \\
\hline $\begin{array}{l}\text { t Critical one- } \\
\text { tail }\end{array}$ & 1.681070703 & 0.000000000077 & \\
\hline $\begin{array}{l}P(T<=t) \text { two- } \\
\text { tail }\end{array}$ & 0.000000000001248 & 1.681070703 & \\
\hline $\begin{array}{l}\text { t Critical two- } \\
\text { tail }\end{array}$ & 2.016692199 & 0.000000000153 & \\
\hline
\end{tabular}

Table 2 Shows a reduced reporting time from an average of 86 hours using paper-based to 8.7 hours using the electronic (digitized) reporting system, and the difference was found to be statistically significant- $\mathrm{p}$-value $<0.01$. Similarly, the turn-around time for digitized reporting system was shorter - 8 days compared to 30 days for the paper-based reporting. The difference was found to be statistically significant, p-value $<0.01$.

\section{Discussion}

The study used a novel approach to conduct and monitor disease surveillance, particularly active surveillance for Acute Flaccid Paralysis (AFP). The study documented a remarkable improvement in the average reporting time for active surveillance when the polio program deployed digitized surveillance reporting system. The average reporting time improved signficantly from 87 hours to 8 hours in the African region across 44 implementing countries. It is also interesting to note that the turn-around time for paper-based reporting, which usually takes 30 days to submit into the database and being reflected for action, was significantly reduced to 8 days at the regional level. The digitization of surveillance reporting has improved visualisation and allowed easier tracking for the monitoring and accountability. 


\section{Real-time feedback and transparent decision making}

The biggest strength of holistic disease surveillance in low-resource settings and weak health systems is real-time reporting. The faster the turn-around time for reporting, the more likely response can be mounted to mitigate an outbreak. The average reporting time improved signficantly from from 87 hours to 8 hours in the African region across 44 implementing countries. A study conducted in Sudan, in 2016, compared the smartphone and paper-based data collection systems on the Burden of Obstructive Lung Disease (BOLD) in Gezira State, a rural state in Sudan. The study concluded that digital data collection provided timely quality data with fewer errors and inconsistencies compared to paper-based data collection(23). Similarly, a study was conducted to evaluate the electronic and paper-pen data collection tools for data quality in a public health survey in a health and demographic site, Ethiopia.(23) The study found that better data quality and efficiency- fewer errors, instant data submission and easy handling, however, implementing agencies need to consider availability of power source, decent internet connection, technical support and security for the mobile device users for full implementation and integration into surveillance system $(23,24)$. Also a similar study in China on comparing digital data collection and paper/pen data collection for infant feeding practices corroborates the same results of better data quality and fewer errors.(25)

\section{Demonstrated accountability enabled system}

Accountability is enabled in the digitised active surveillance system via auto-collected geocoordinates whenever a health worker visits a health facility to conduct an active case search. This intrinsic accountability-enabled method ensures that the right facility is visited as reported, recorded and feedback to improve the system is recorded alongside all the primary datasets of conducting. The map of districts visited across the region is aggregated based on geocoordinates collected as metadata during the digitized active surveillance visit. From 2017 to 2020, there have been over 380,000 geo-coded active surveillance visits in 44 countries in the region. This huge dataset helps addressing accountability issues by tracking visits done by designation and when it is done with an emphasis on supporting districts and or colleagues with poor surveillance practice. An example is demonstrated in Figure 3 showing a ranking of districts/Province visited every 14 days, a quasi-indicator for tracking if disease surveillance has been conducted in every district in the African region. The "red" districts are prioritised and shared with country focal persons for poor performing districts/province/for action on a weekly bases.

\section{New capabilities to compare and superimpose Surveillance indicators (Performance vs Process indicators)}

One of the key shortcomings of monitoring polio surveillance hitherto digitised surveillance is comparing performance indicators with the processes that lead to this performance. For example, Non Polio AFP rates is an important indicator for polio surveillance performance. It involves using population factor in a district to determine the number of children under 15 years that should be identified with AFP if there is optimal surveillance in place. This indicator is mostly enough for indicating if a district has seen a child under 15 years with AFP but does not answer the question of how extensive the search for children with 
any form of AFP. In otherword, it does not address the process indicator. Overlaying the NPAFP rates with the active surveillance visits in a district reveals three possible trends that add actionable insights to the surveillance system.

i. Insufficient supportive visits to focal sites in a district (planning and accountability issues)

ii. Over-visits to focal sites in the district (prioritization and mapping issues)

iii. Optimal visits that can sustain good surveillance indicators

Figure 4 shows an example of superimposing active surveillance visits and NPAFP revealing gaps in Polio Surveillance across the African region. With this interactive output, country/province/district level focal persons can zoom into the areas of poor performance to see both indicators interactively.

\section{Interactivity,visualizations and Wider Reach}

Web interactivity refers to interactive features that are embedded on websites that offer an exchange of information either between communication technology and users or between users using technology(26) . This type of interactivity evolves with new developments of website interfaces. A review by Flew Terry defined interactivity in new media distinguishing itself from old media by implementing participation from users rather than passive consumption.

Developing responsiveness of visualization to users for slicing and dicing the digitized surveillance data was a key consideration in the system development. It was envisaged that partners in Global Polio Eradication Initiative (GPEI) would be interacting with the active surveillance data to be updated on surveillance progress and gaps in real-time. This means that visualizations need to show, in one glimpse, understandable depictions of reality, stripped of its messiness and complexities(27). Smart Interactive Televisions were deployed to all 47 countries in the African region to facilitate interactivity with the webbased applications of the active surveillance aggregated data. An example of using the smart interactive screen is seen in figure 5, where WHO staff in the regional office are interacting with the screen to slice and dice outbreak data from Democratic Republic of Congo.

This interaction with the data is also evaluated using a number of hits on the visualisation of the active surveillance maps, charts and dashboard. The geographic location of the end- user is automatically geotagged and replicated on the map, as seen in Figure 6 . The map shows that 35 countries are regularly viewing the trends of the interactive maps and dashboards on a week-by-week basis. Precisely, 21(45\%) countries in the African region are reported to be utilising these data as expected. Importantly, when these data are disaggregated, 12 (86\%) of the 14 high-risk countries ( as categorised based on polio risk and population immunity risks) are regularly interacting with the web-based interactive monitoring of the active case search suggesting a strong use of data for action.

\section{Conclusion}


Ending polio entails that decision-making from surveillance activities has to be faster with an excellent turn-around time for collecting surveillance information in near real-time. Analysing data, especially triangulating from many sources, can be complex, and data is an important element needed in this complex process. Hence, digitisation of active surveillance has improved the interactivity of teams with the disease surveillance data, fostered accountability, improved the usability and wider reach of the data. Thus, policy and decision-makers can better conduct a strategic evaluation of the disease surveillance situation and gap analyses via interactive visualisations and decision support system. These digitised surveillance systems with interactive visualisations provided this perspective to polio eradication initiative in Africa. Indeed, it is a veritable platform to visualise interactive maps, charts and dashboard, and evidence of active surveillance at the focal site level for all polio surveillance processes.

\section{Declarations}

\section{Ethics approval and consent to participate}

Ethics approval for this paper is premised on the overaching agreement on use of data by WHO with countries and publishing in non-WHO publications that are authored or co-authored by WHO staff CC BY 3.0 IGO or CC BY-NC 3.0 IGO.Also all study participants were over the age of 18 years or older and provided electronic informed consent.

All procedures performed in studies involving human participants were in accordance with the ethical standards of the institutional research committee and with the 1964 Helsinki declaration and its later amendments or comparable ethical standards.

\section{Consent to publish}

Informed consent was obtained from all individual participants included in the study and photos

\section{Availability of data and materials}

The data utilized are accessible from the corresponding author upon reasonable request.

\section{Competing interests}

The authors declare no competing interests.

\section{Authors' Contributions}

AG, $\mathrm{BI}$ and TJ conceived and wrote the first draft of the manuscript. All authors read and provided important inputs for all drafts of the manuscript, agreed to be accountable for all aspects of the work, and approved the final draft of the manuscript for publication.

\section{Funding}


The Bill and Melinda Gates Foundation has sponsored this project without participating in any way in the design, data analysis or writing of this article.

\section{Acknowledgements}

We thank the different Country Ministries of Health and health workers who have continuously made the polio eradication agenda a personal mission. The authors alone are responsible for the views expressed in this article, which do not necessarily represent the views, decisions, or policies of the institutions with which they are affiliated.

\section{Conflicts of Interest}

None declared.

\section{References}

1. Van Den Ent MMVX, Mallya A, Sandhu H, Anya BP, Yusuf N, Ntakibirora M, et al. Experiences and Lessons from Polio Eradication Applied to Immunization in 10 Focus Countries of the Polio Endgame Strategic Plan. J Infect Dis. 2017;216(Suppl 1):S250-9.

2. Cochi SL, Freeman A, Guirguis S, Jafari H, Aylward B. Global polio eradication initiative: Lessons learned and legacy. J Infect Dis. 2014;210(Suppl 1):S540-6.

3. Orenstein WA, Gellin BG, Beigi RH, Despres S, Larussa PS, Lynfield R, et al. Enhancing the work of the department of health and human services national vaccine program in global immunization: Recommendations of the national vaccine advisory committee. Public Health Rep [Internet]. 2014 Sep 1 [cited 2020 Aug 27];129(Suppl 3):12-20. Available from: https://www.ncbi.nlm.nih.gov/pmc/articles/PMC4121882/

4. Tesfaye B, Makam JK, Sergon K, Onuekwusi I, Muitherero C, Sowe A. The role of the Stop Transmission of Polio (STOP) program in developing countries: the experience of Kenya. [cited 2020 Aug 27]; Available from: https://doi.org/10.1186/s12889-020-09196-1

5. Tegegne SG, Shuaib F, Braka F, Mkanda P, Erbeto TB, Aregay A, et al. The role of supportive supervision using mobile technology in monitoring and guiding program performance: a case study in Nigeria, 2015-2016. [cited 2020 Aug 27]; Available from: https://doi.org/10.1186/s12889-0186189-8

6. World Health Organization. Polio Eradication \& Endgame Strategic Plan 2013-2018: Financial Resource Requirements. 2014; Available from: http://www.polioeradication.org/Portals/0/Document/Financing/FRR_EN_A4.pdf

7. Clarke A, Blidi N, Dahn B, Agbo C, Tuopileyi R, Rude MJ, et al. Strengthening acute flaccid paralysis surveillance post Ebola virus disease outbreak 2015 - 2017: the Liberia experience. Pan Afr Med J. 2019;33(Supp 2):2. 
8. Akpan GU, Tegegne SG, Erbeto T, Daramola O, Braka F, Mkanda P. Use of Mobile Phone and Facilitybased Server Technology in Routine Immunization and Disease Surveillance Activities in Nigeria: Strengthening Polio Surveillance. In: 2018 International Conference on Smart Computing and Electronic Enterprise (ICSCEE). 2018. p. 1-8.

9. Hofman W, Rajagopal M. A technical framework for data sharing. J Theor Appl Electron Commer Res. 2014;9(3):45-58.

10. Ingale Y, Durge R, Mulgi S, Patil BA. Study of Big Data Visualization Software Tools Used By Businesses. 2019;7(2):106-7.

11. Yur E, Vasil V. Analytical Review of Data Visualization Methods in Application to Big Data. J Electr Comput Eng. 2013;2013:Article ID 969458.

12. Tominc P, Burian J, Exploration S. Spationomy. Africa Health News. 2019;

13. Ko I, Chang H. Interactive visualization of healthcare data using Tableau. Healthc Inform Res. 2017;23(4):349-54.

14. Alam JR, Sajid A, Talib R, Niaz M. A Review on the Role of Big Data in Business. Int J Comput Sci Mob Comput. 2014;34(4):446-53.

15. Global Polio Eradication Initiative. Ending polio against all odds - GPEI [Internet]. GPEI News-post. 2019 [cited 2020 Aug 27]. Available from: http://polioeradication.org/news-post/ending-polioagainst-all-odds/

16. Decker M (Michael), Ladikas M (Miltos), zur Erforschung von Folgen Wissenschaftlich-Technischer Entwicklungen Bad Neuenahr-Ahrweiler GmbH EA. Bridges between science, society and policy: technology assessment - methods and impacts [Internet]. Berlin: Springer; 2004. Available from: http://www.loc.gov/catdir/toc/fy0802/2007462986.html

17. Hartung C, Anokwa Y, Brunette W, Lerer A, Tseng C, Borriello G. Open Data Kit: Tools to Build Information Services for Developing Regions. Proc Int Conf Inf Commun Technol Dev. 2010;1-11.

18. Tomlinson M, Solomon W, Singh Y, Doherty T, Chopra M, ljumba P, et al. The use of mobile phones as a data collection tool: a report from a household survey in South Africa. BMC Med Inform Decis Mak [Internet]. 2009;9(1):51. Available from: http://www.biomedcentral.com/1472-6947/9/51

19. Maduka O, Akpan G, Maleghemi S. Using Android and Open Data Kit Technology in Data Management for Research in Resource-Limited Settings in the Niger Delta Region of Nigeria: CrossSectional Household Survey. JMIR mHealth uHealth. 2017;

20. Soucie JM. Public Health Surveillance and Data Collection: General Principles and Impact on Hemophilia Care. Hematology. 2015;17(0 1):1-6.

21. Roman D, Nikolov N, Putlier A, Sukhobok D, Elvesæter B, Berre A, et al. DataGraft: One-stop-shop for open data management. Semant Web. 2018;9(4):393-411.

22. Birkhead GS, Klompas M, Shah NR. Uses of electronic health records for public health surveillance to advance public health. Annu Rev Public Health. 2015;36:345-59. 
23. Zeleke AA, Worku AG, Demissie A, Otto-Sobotka F, Wilken M, Lipprandt M, et al. Evaluation of electronic and paper-pen data capturing tools for data quality in a public health survey in a health and demographic surveillance site, Ethiopia: Randomized controlled crossover health care information technology evaluation. J Med Internet Res. 2019;21(2).

24. Cai L, Zhu Y. The challenges of data quality and data quality assessment in the big data era. Data Sci J. 2015;14:1-10.

25. Zhang S, Wu Q, Van Velthoven QWMHMMT, Chen L, Car J, Rudan I, et al. Smartphone versus penand-paper data collection of infant feeding practices in rural China. J Med Internet Res. 2012;14(5).

26. Andhini NF. anNo Title No Title [Internet]. Vol. 53, Journal of Chemical Information and Modeling. 2017. p. 1689-99. Available from: https://en.wikipedia.org/wiki/Interactivity

27. Editor B, Kennedy H. Data Visualization in Society. Data Vis Soc. 2020;

\section{Tables}

Due to technical limitations, table 1 is only available as a download in the Supplemental Files section.

\section{Figures}

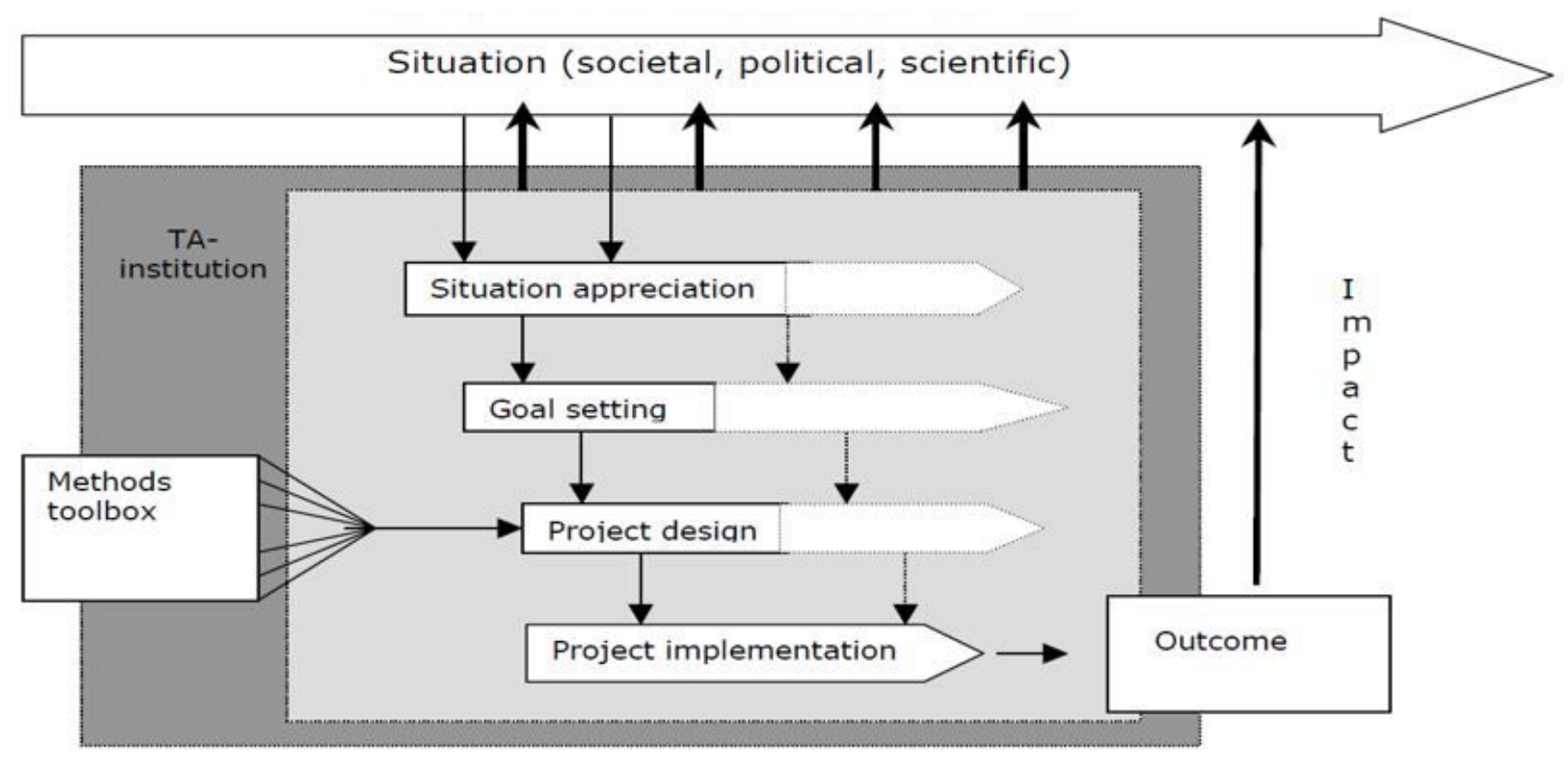

\section{Figure 1}

Decker and Ladikas (Eds), 2004. Bridges between Science, Society and Policy. Technology Assessment Methods and Impacts, Springer. 


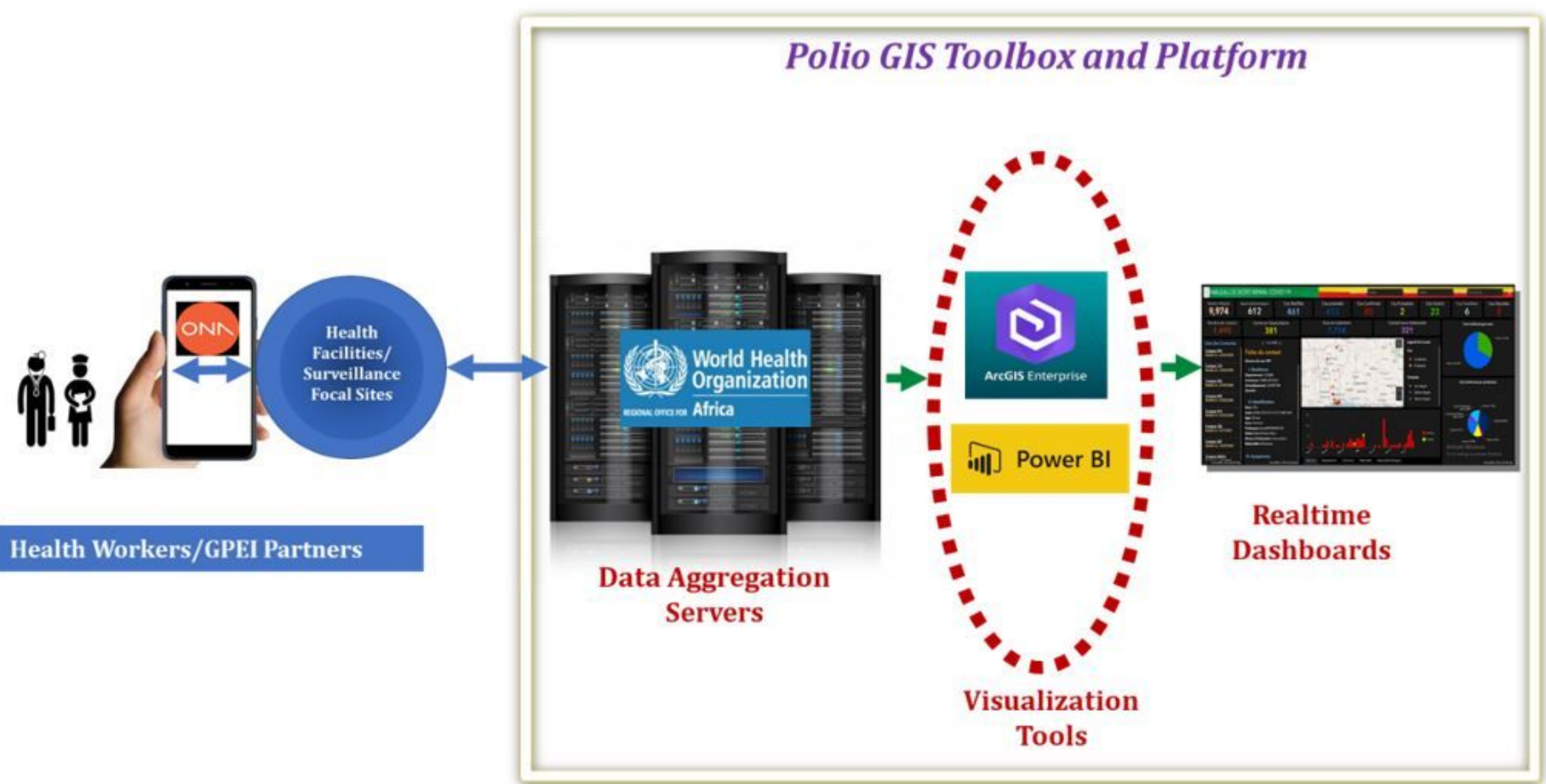

\section{Figure 2}

Active surveillance architecture showing processes

GEOGRAPHIC COVERAGE OF REGIONAL ACTIVE SURVEILLANCE VISITS JAN TO JUN 2020 (N 67,588)

DISTRIBUTION OF VISITS BY PROVINCE

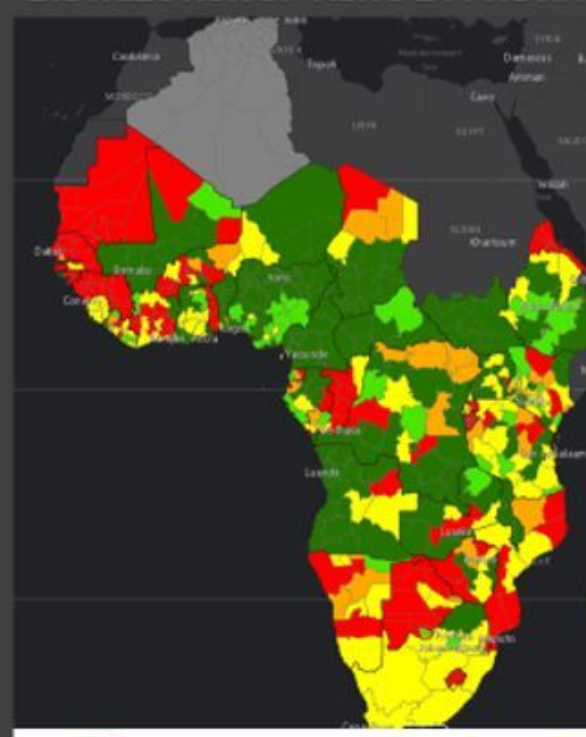

Active Survelllance in the last 14 days Active Surveillance the last month
DISTRIBUTION OF VISTISBY DISTRICT

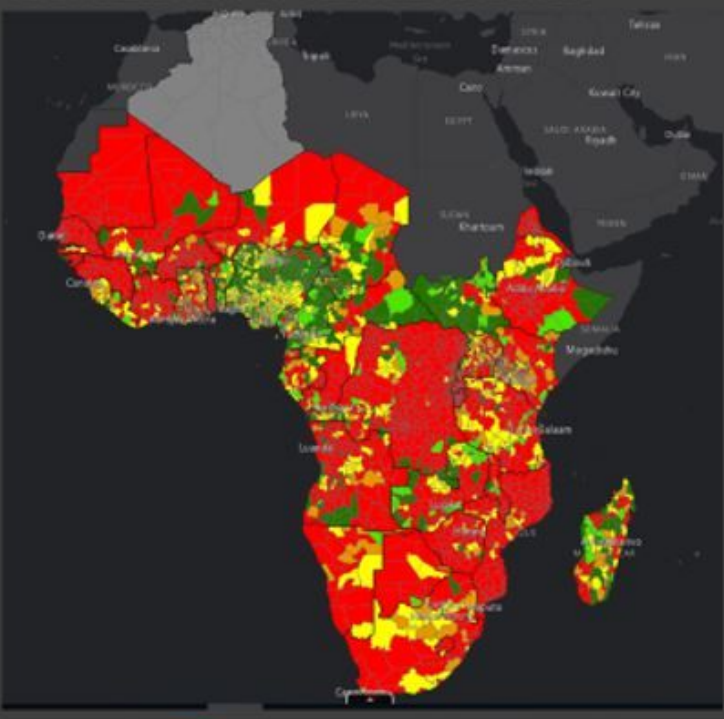

ctive Survelllance in the last 2 months

Active Surveillance in the last 3 months

No Active Survelllance in $>3$ months Not implementing eSURV or ISS 


\section{Figure 3}

Maps of active surveillance using the mandatory 14 days policy to assess surveillance coverage and gaps by districts and province in the African Region Note: The designations employed and the presentation of the material on this map do not imply the expression of any opinion whatsoever on the part of Research Square concerning the legal status of any country, territory, city or area or of its authorities, or concerning the delimitation of its frontiers or boundaries. This map has been provided by the authors.

\section{AFRO: Non Polio AFP(NPAFP) rates comparison with ISS visits for Jan- Oct 2018}

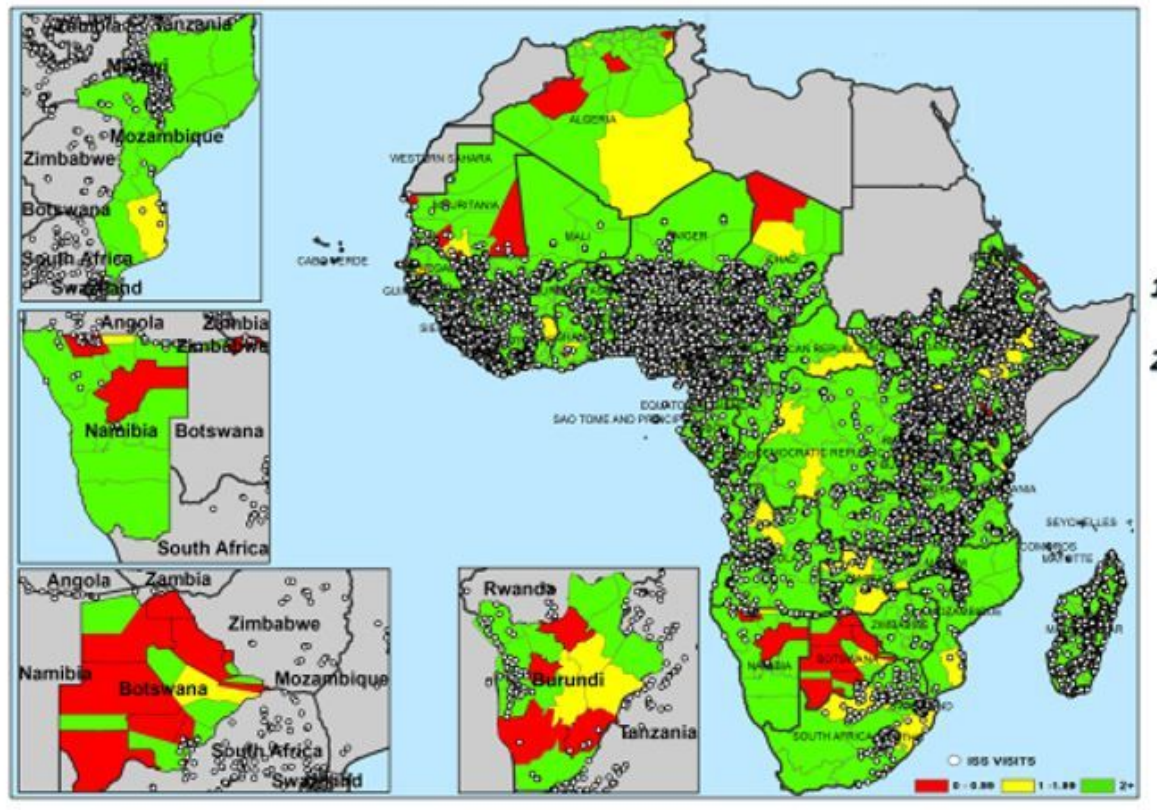

\section{Quick notes}

1. Where we are NOT doing active case search have pockets of low NPAFP rates

2. This is seen in Mozambique , Botswana, Burundi, Central African republic, Chad, Mauritania,DRC and Algeria

Figure 4

Superimposed map of Non Polio AFP Rates with active surveillance visits for surveillance visits prioritization Note: The designations employed and the presentation of the material on this map do not imply the expression of any opinion whatsoever on the part of Research Square concerning the legal status of any country, territory, city or area or of its authorities, or concerning the delimitation of its frontiers or boundaries. This map has been provided by the authors. 


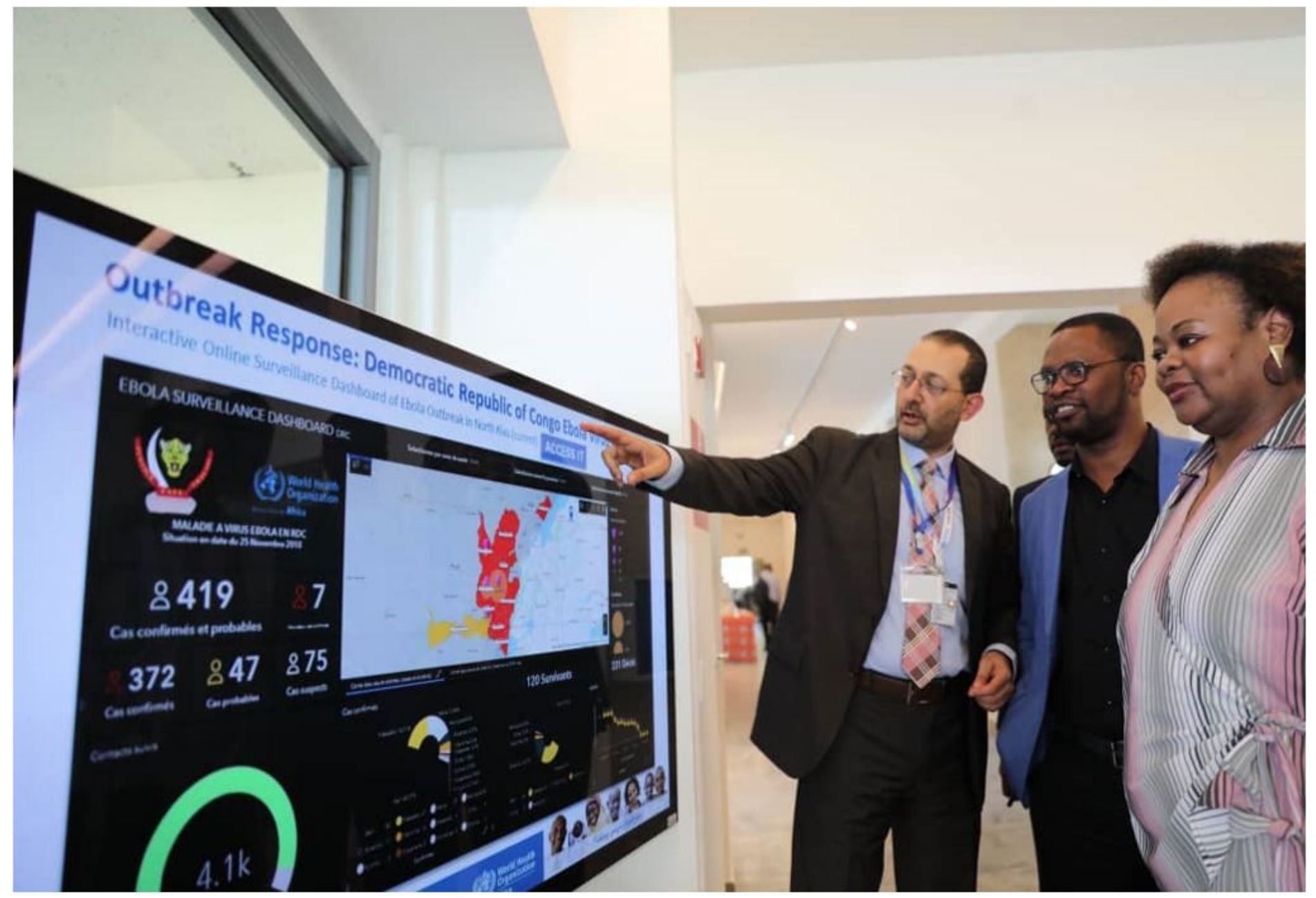

Figure 5

Authors,2020 .Illustrating how AFRO teams used Smart devices to interactively navigate the digitized surveillance visualization to illustrate performance and gaps 


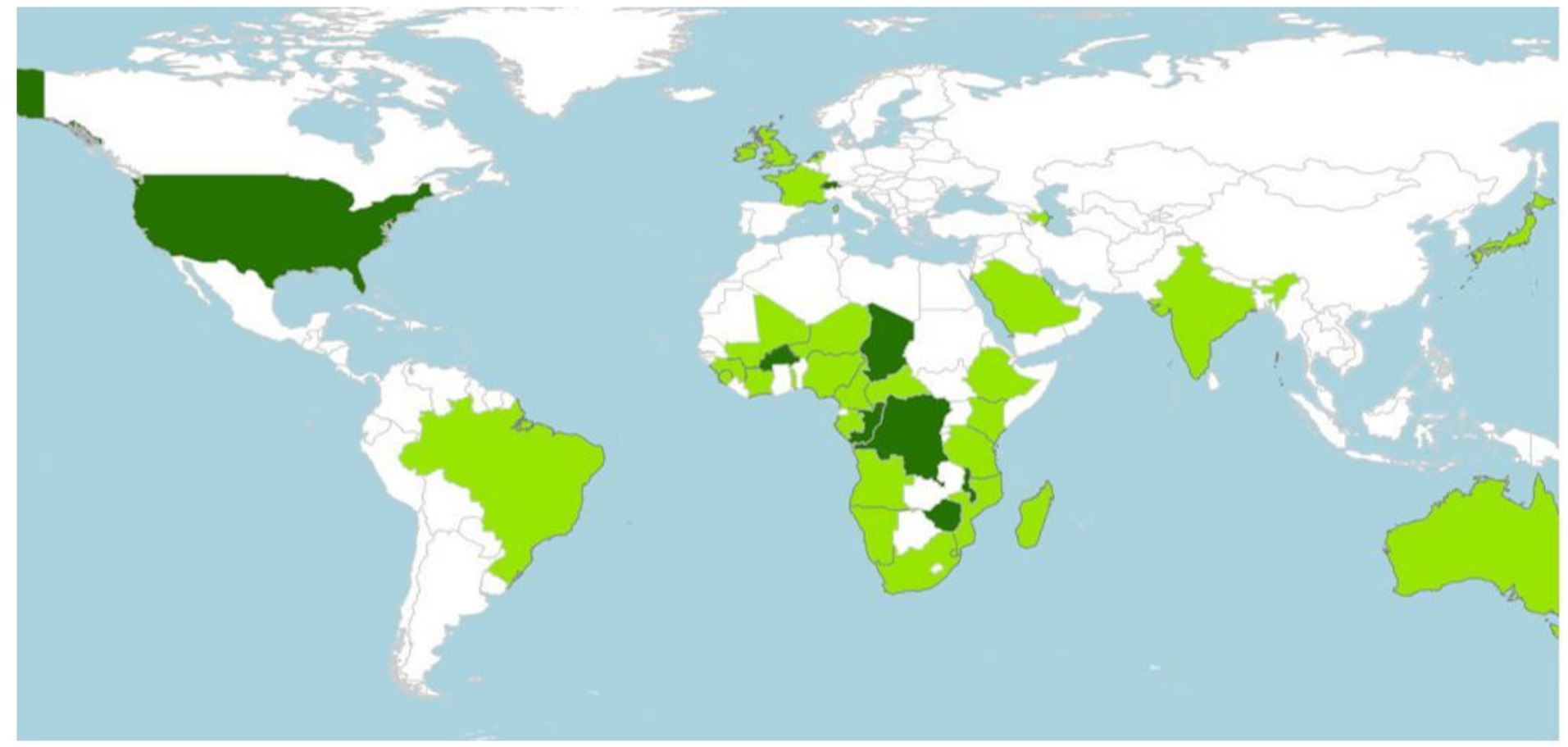

Figure 6

Automated monitoring map of countries utilizing the web products from the visualization platforms for the digitised active surveillance. Note: The designations employed and the presentation of the material on this map do not imply the expression of any opinion whatsoever on the part of Research Square concerning the legal status of any country, territory, city or area or of its authorities, or concerning the delimitation of its frontiers or boundaries. This map has been provided by the authors.

\section{Supplementary Files}

This is a list of supplementary files associated with this preprint. Click to download.

- Table1.jpg 